\title{
Chemical interaction at the buried silicon/zinc oxide thin-film solar cell interface as revealed by hard $x$-ray photoelectron spectroscopy
}

M. Wimmer ${ }^{*}, 1$, D. Gerlach ${ }^{1}$, R.G. Wilks ${ }^{1}$, S. Scherf ${ }^{1}$, R. Félix ${ }^{1}$, C. Lupulescu ${ }^{2}$, F. Ruske ${ }^{1}$, G. Schondelmaier $^{1}$, K. Lips ${ }^{1}$, J. Hüpkes ${ }^{3}$, M. Gorgoi ${ }^{1}$, W. Eberhardt ${ }^{1,2}$, B. Rech ${ }^{1}$, and M. Bär ${ }^{\dagger, 1,4}$

\footnotetext{
${ }^{1}$ Helmholtz-Zentrum Berlin für Materialien und Energie GmbH, Hahn-Meitner-Platz

1, 14109 Berlin, Germany

${ }^{2}$ Institute for Optics and Atomic Physics, Technische Universität Berlin,

Hardenbergstr. 36, 10623 Berlin, Germany

${ }^{3}$ Institute for Energy Research, Forschungszentrum Jülich GmbH, Leo-Brandt-Straße,

52425 Jülich, Germany

${ }^{4}$ Institut für Physik und Chemie, Brandenburgische Technische Universität Cottbus,

Konrad-Wachsmann-Allee 1, 03046 Cottbus, Germany
}

$\underline{\text { Highlights }}$

- We used HAXPES to identify chemical interactions at the buried silicon/aluminum-doped zinc oxide thin-film solar cell interface.

- The results indicate a diffusion of zinc and aluminum into the silicon upon annealing procedures which are part of the solar cell processing.

- The contamination of the silicon may be detrimental for the solar cell performance.

\footnotetext{
${ }^{*}$ Corresponding author. Email: mark.wimmer@helmholtz-berlin.de.

${ }^{+}$Corresponding author. Email: marcus.baer@helmholtz-berlin.de
} 


\title{
Chemical interaction at the buried silicon/zinc oxide thin-film solar cell interface as revealed by hard $x$-ray photoelectron spectroscopy
}

\author{
M. Wimmer ${ }^{*}, 1$, D. Gerlach ${ }^{1}$, R.G. Wilks ${ }^{1}$, S. Scherf ${ }^{1}$, R. Félix ${ }^{1}$, C. Lupulescu² ${ }^{2}$, F. Ruske ${ }^{1}$, G. \\ Schondelmaier $^{1}$, K. Lips ${ }^{1}$, J. Hüpkes ${ }^{3}$, M. Gorgoi ${ }^{1}$, W. Eberhardt ${ }^{1,2}$, B. Rech ${ }^{1}$, and M. Bär ${ }^{\dagger, 1,4}$
}

\author{
${ }^{1}$ Helmholtz-Zentrum Berlin für Materialien und Energie GmbH, Hahn-Meitner-Platz \\ 1, 14109 Berlin, Germany \\ ${ }^{2}$ Institute for Optics and Atomic Physics, Technische Universität Berlin, \\ Hardenbergstr. 36, 10623 Berlin, Germany \\ ${ }^{3}$ Institute for Energy Research, Forschungszentrum Jülich GmbH, Leo-Brandt-Straße, \\ 52425 Jülich, Germany \\ ${ }^{4}$ Institut für Physik und Chemie, Brandenburgische Technische Universität Cottbus, \\ Konrad-Wachsmann-Allee 1, 03046 Cottbus, Germany
}

Hard $x$-ray photoelectron spectroscopy (HAXPES) is used to identify chemical interactions (such as elemental redistribution) at the buried silicon/aluminum-doped zinc oxide thin-film solar cell interface. Expanding our study of the interfacial oxidation of silicon upon its solid-phase crystallization (SPC), in which we found zinc oxide to be the source of oxygen, in this investigation we address related redistribution processes involving zinc and aluminum. In particular, we observe an increase of zinc- and aluminum-related HAXPES signals after SPC of the deposited amorphous silicon thin films. The simplest model to explain this was found to be a reduction of the effective thickness of the attenuating silicon capping layer, which was interpreted as an indication for zinc and aluminum diffusion into the silicon emitter. A quantitative analysis revealed that this elemental redistribution in the proximity of the silicon/aluminum-doped zinc oxide interface seems to be more pronounced for aluminum than for zinc.

\footnotetext{
${ }^{*}$ Corresponding author. Email: mark.wimmer@helmholtz-berlin.de.

+ Corresponding author. Email: marcus.baer@helmholtz-berlin.de
} 


\section{Introduction}

Silicon thin-film solar cells offer numerous advantages over wafer-based photovoltaics (PV), particularly in terms of decreased material consumption and lowcost production methods. The power conversion efficiencies of silicon thin-film solar cells are, however, still significantly below those of wafer-based technologies [1]. This indicates that the main challenges of this thin-film PV technology are to form highquality absorber layers with low defect concentrations and optimally-designed interfaces [2].

There are several approaches to preparing silicon thin-films of sufficient quality for use in solar cell devices. One route is to directly deposit the silicon layers in the form in which they will be used in the device structure. Commonly, the method used for deposition of such hydrogenated amorphous silicon (a-Si:H) [3] or microcrystalline silicon ( $\mu \mathrm{c}-\mathrm{Si}: \mathrm{H})[4]$ absorber layers is plasma-enhanced chemical vapor deposition (PECVD). Another route is to deposit the (amorphous) Si thin-films as precursory layers, the quality and characteristics of which are then improved using postdeposition treatments. This approach principally allows employing rapid deposition techniques instead of PECVD, enabling shortened production times and thus a potential decrease in cost.

One promising polycrystalline silicon thin-film solar cell concept employing the latter preparation approach is based on depositing amorphous silicon films which are subsequently crystallized [5]. Different methods for crystallizing the material include thermally-induced solid-phase crystallization (SPC), laser crystallization, and electron beam (e-beam) crystallization [6]. SPC is the most commonly employed technique, and has already successfully been used in industrial production resulting in solar cell modules with $10.4 \%$ efficiency [7]. This represents the highest performance of devices based on solid-phase crystallized silicon to date. However, it is expected that efficiency gains and cost reductions could be realized by replacing the employed complicated point-contact electrical connection scheme [7] with a transparent contact, such as aluminum-doped zinc oxide (ZnO:Al). A schematic presentation of such a cell concept is shown in Fig. 1; here the silicon thin films are prepared onto the $\mathrm{ZnO}: \mathrm{Al}$ layers deposited on a glass substrate (coated with a diffusion barrier). Besides allowing a simpler contacting scheme, using ZnO:Al may facilitate the easy implementation of light trapping structures (e.g., via wet-chemical etching [8]), 
expected to lead to further efficiency improvements. Light-trapping structures are especially needed for crystalline silicon thin-film solar cells, increasing the absorption efficiency of this indirect semiconductor material. While it has been shown that solidphase crystallized e-beam evaporated silicon can be used instead of solid-phase crystallized PECVD deposited silicon without detriment to the performance of respective solar cells [9], using a transparent ZnO:Al contact layer decreases the efficiency of the device markedly [10]. In order to determine the origin of the detrimental impact on device performance, we have focused our attention on the study of the effects of the thermal SPC treatment on the Si/ZnO:Al interface. Previously, we used hard x-ray photoelectron spectroscopy (HAXPES) to identify an SPC-enhanced interfacial oxidation of the silicon [11]; in this contribution, we will review that study using it as the basis to also examine annealing-induced changes in the zinc and aluminum distributions in the proximity of the Si/ZnO:Al interface by HAXPES.

\section{Experimental}

The model system prepared for the study of the buried Si/ZnO:Al interface consisted of $12 \mathrm{~nm}$ of a-Si:H doped with phosphorous [a-Si:H(P)] deposited on top of a $\sim 800$ $\mathrm{nm}$ thick ZnO:Al film. The ZnO:Al was deposited on a Corning Eagle XG glass substrate by rf-magnetron sputtering from a ceramic $\mathrm{ZnO}: \mathrm{Al}_{2} \mathrm{O}_{3}$ target containing 1 wt. $\% \mathrm{Al}_{2} \mathrm{O}_{3}(\sim 0.8$ at.\% Al). The initial substrate temperature was approximately 300 ${ }^{\circ} \mathrm{C}$. Note that no diffusion barrier between the glass substrate and the $\mathrm{ZnO}$ :Al layer was used. In order to have accurate control of the thickness of the deposited silicon thin film, we used PECVD (instead of e-beam evaporation) with diluted $\mathrm{SiH}_{4}$ and $\mathrm{PH}_{3}$ as precursors. During silicon deposition, the substrate temperature was $190^{\circ} \mathrm{C}$. Note that a silicon thickness of $12 \mathrm{~nm}$ was chosen because the crystallization of thinner films does not resemble that of thicker films as used in the solar cell; and $12 \mathrm{~nm}$ was essentially the thickest that the film could be while allowing the $\mathrm{ZnO}$ :Al substrate and buried Si/ZnO:Al interface to reasonably be studied with HAXPES. The here investigated samples were the same as used for our study of the silicon oxidation at the Si/ZnO:Al interface described in Ref. [11]. 
The SPC treatment of the a-Si:H(P)/ZnO:Al layer stack was performed in a nitrogenpurged tube furnace using a plateau temperature of $650{ }^{\circ} \mathrm{C}$ and a plateau time of $24 \mathrm{~h}$. Note that these SPC parameters slightly differ from the standard plateau time and temperature $\left(20 \mathrm{~h}\right.$ and $600{ }^{\circ} \mathrm{C}$, respectively). This modified SPC process was used because a previous study showed that these parameters are most beneficial to the electrical properties of the underlying $\mathrm{ZnO}: \mathrm{Al}$ layer [12]; exploring the origin of this improvement was one motivation of the current study.

All measurements were conducted at the KMC-1 bending magnet beamline at the BESSY II synchrotron facility using the HIKE endstation [13], which is equipped with a SCIENTA R4000 electron analyzer capable of measuring kinetic energies up to 10 $\mathrm{keV}$. All measurements were conducted using a pass energy of $200 \mathrm{eV}$, giving a total experimental resolution of approximately $0.2 \mathrm{eV}$ at $2010 \mathrm{eV}$ excitation energy [14]. For our measurements, the excitation energy was set to $2010 \mathrm{eV}$ using the $\mathrm{Si}$ (111) double crystal monochromator; measurements at 6030 and $8040 \mathrm{eV}$ excitation energy were conducted using its $3^{\text {rd }}$ - and $4^{\text {th }}$-order harmonics. The 3000,4000 , and $5000 \mathrm{eV}$ excitation energies used the $\mathrm{Si}$ (111) crystal as well. For energy calibration the binding energy of the $\mathrm{Au} 4 \mathrm{f}$ core level of a clean gold reference was measured for each excitation energy.

\section{Results and Discussion}

In an earlier study [11], we could reveal the annealing-induced oxidation of the silicon at the Si/ZnO:Al interface by comparing HAXPES spectra before and after SPC. This analysis was based on measuring the $\mathrm{Si}$ 1s core level spectra at five different excitation energies between 2010 and $8040 \mathrm{eV}$ and comparing the relative intensities of the spectral contributions of $\mathrm{Si}-\mathrm{Si}$ and $\mathrm{Si}_{-} \mathrm{O}_{x}$ bonds to the photoemission line [Fig. 2]. After performing the SPC treatment in a nitrogen-purged furnace (as it is done for solar cell processing) the increased degree of silicon surface oxidation dominates the spectral changes of the Si 1 s line at first sight. However, the detailed quantification of the oxidation - using the intensity ratio of the $\mathrm{Si} 1 \mathrm{~s} \mathrm{Si}-\mathrm{O}_{x}$ contribution to that related to Si-Si bonds as a function of the electron inelastic mean free path (IMFP, from Ref. [15]) - revealed that a silicon oxidation also takes place at the Si/ZnO:Al interface in agreement with our analysis using soft x-ray emission spectroscopy [16]. In 
particular, the comparison to a surface oxidation model system (an oxidized silicon wafer in which oxidation occurs exclusively at the surface) and an in-situ SPC annealing experiment in ultra-high vacuum (UHV) allowed the above conclusion to be drawn. (For a more detailed description and discussion see Ref. [11].) Another result was that the formation of these interfacial $\mathrm{Si}-\mathrm{O}_{x}$ bonds takes place at the expense of $\mathrm{Zn}-\mathrm{O}$ bonds, which points to $\mathrm{ZnO}: \mathrm{Al}$ as the oxygen source for the interface oxidation. The reduction of the number of $\mathrm{Zn}-\mathrm{O}$ bonds is concurrent with the aforementioned improvement of the electronic properties of the buried ZnO:Al layer [12] and the formation of $\mathrm{Si}-\mathrm{O}_{x}$ bonds at the interface might offer an explanation for the overall degradation in performance of respective solar cells [10]. On the basis of the revealed interfacial silicon oxidation, we expand our study of the Si/ZnO:Al interface to explore additional (related) chemical interactions in the following.

To determine whether the SPC process induces interfacial chemical interaction processes involving zinc, we measured $\mathrm{Si} 2 \mathrm{~s}$ and $\mathrm{Zn} 3 \mathrm{~s}$ core level spectra of the $\mathrm{Si} / \mathrm{ZnO}$ :Al layer stack, before and after annealing, for six excitation energies between 2010 and $8040 \mathrm{eV}$. The spectra are normalized to the maximum intensity of the Si 2s $\mathrm{Si}$-Si line and are displayed in Fig. 3. For the lowest excitation energy $(2010 \mathrm{eV}) \mathrm{no}$ contribution of $\mathrm{Zn}$ 3s can be seen before or after SPC, confirming that the silicon film completely covers the ZnO:Al layer and did not form fissures upon annealing. In the spectra taken before annealing, the contribution of the $\mathrm{Zn} 3$ s core level becomes more significant with increasing excitation energy and is most pronounced for the highest excitation energy $(8040 \mathrm{eV})$. After annealing, the relative intensity of the $\mathrm{Zn}$ 3s contribution is enhanced for $h v \geq 3000 \mathrm{eV}$; especially visible in the enlarged presentation of the $\mathrm{Zn}$ 3s line in Fig. 3b. This points to a SPC-induced redistribution of zinc in the proximity of the $\mathrm{Si} / \mathrm{ZnO}: \mathrm{Al}$ interface; this will be discussed in more detail in conjunction with Fig. 6. In addition to the $\mathrm{Si} 2 \mathrm{~s} \mathrm{Si-Si} \mathrm{main} \mathrm{contribution,} \mathrm{an}$ enhanced $\mathrm{Si}-\mathrm{O}_{x}$ contribution can be seen on the high-binding energy side of the $\mathrm{Si}-\mathrm{Si}$ contribution, indicating that additional silicon oxide has formed due to the annealing procedure. The intensity of this $\mathrm{Si}-\mathrm{O}_{x}$ contribution decreases rapidly with increasing excitation energy in contrast to the increasing intensity of the $\mathrm{Zn}$ 3s line. This behavior is consistent with the enhanced surface oxidation of the silicon due to the above-mentioned annealing in the furnace. 
Furthermore, the Si 2s signal shifts significantly to higher binding energy values in all cases. This SPC-induced Si 2s binding energy shift (as a function of IMFP) is compared to that of the $\mathrm{Zn} 3 \mathrm{~s}$ line in Fig. 4. While the Si 2s core level binding energy shifts to higher values by an average value of $(0.35 \pm 0.14) \mathrm{eV}$, any shift of the $\mathrm{Zn} 3 \mathrm{~s}$ core levels is much smaller and mainly (i.e., within the error bars) constant. Only a small fraction of the dopants are activated in a-Si:H(P) [17], and so the observed shift of the Si 2 s core level likely reflects a shift of the Fermi level due to the an SPCinduced activation of the phosphor dopants in crystalline silicon.

In addition to the SPC-induced chemical interaction at the Si/ZnO:Al interface involving $\mathrm{Zn}$, the behavior of aluminum was studied: the Al 1s core level spectra of the same Si/ZnO:Al sample before and after SPC annealing were measured using five different excitation energies. The spectra are shown in Fig. 5 normalized to the integrated background in the range of the $\mathrm{Al} 1 \mathrm{~s}$ signal. For the lowest excitation energies $(2010,3000 \mathrm{eV})$ no Al 1s photoemission line can be identified before or after SPC, confirming (again) that the silicon film completely covers the $\mathrm{ZnO}$ :Al layer not forming fissures upon annealing. In the spectra taken before annealing, the contribution of the $\mathrm{Al}$ 1s core level becomes more significant with increasing excitation energy and is most pronounced for the highest excitation energy (6030 $\mathrm{eV})$. After annealing, the relative Al 1s intensity contribution is significantly larger, indicating a SPC-induced redistribution of aluminum in the proximity of the Si/ZnO:Al interface.

In order to quantify the degree of chemical interaction at the Si/ZnO:Al interface, the SPC-induced increase of the (relative) intensities of the $\mathrm{Zn} 3 \mathrm{~s}$ and $\mathrm{Al}$ 1s line is considered to be due to a decrease in signal attenuation by the silicon capping layer in the following. Note that the SPC-induced changes of the silicon capping layer structure and the observed higher degree of surface oxidation cannot explain the observed increase of zinc- and aluminum-related photoemission line intensities [18].

The ratio of the normalized intensities after $\left(\mathrm{I}_{\mathrm{SPC}}\right)$ and before $\left(\mathrm{I}_{\mathrm{AD}}\right)$ annealing for the $\mathrm{Zn} 3 \mathrm{~s}$ (normalized to the overall $\mathrm{Si} 2 \mathrm{si} \mathrm{Si}$ Si and $\mathrm{Si}-\mathrm{O}_{x}$ contribution) and $\mathrm{Al}$ 1s (normalized to the background) core levels is shown as a function of the electron IMFP in silicon (from Ref. [15]) in Fig. 6. The simplest model to explain the decrease of the intensity ratios with increasing electron IMFP is a reduction of the effective 
thickness of the attenuating silicon capping layer by $\Delta \mathrm{x}=\mathrm{X}_{\mathrm{AD}}-\mathrm{x}_{\mathrm{SPC}}$ with $\mathrm{X}_{\mathrm{AD}}$ and $\mathrm{X}_{\mathrm{SPC}}$ being the effective silicon capping layer thickness before and after SPC, respectively:

$$
\frac{\mathrm{I}_{\mathrm{SPC}}}{\mathrm{I}_{\mathrm{AD}}}=\exp \left(\frac{\Delta \mathrm{x}}{\mathrm{IMFP}}\right)
$$

This can be interpreted as being indicative for a diffusion of zinc and aluminum into the silicon layer. Trend lines for $\Delta x=1.3$ and $3.0 \mathrm{~nm}$ were calculated using Eq. (1) and are shown as dashed and solid line in Fig. 6. The comparison with the experimental intensity ratios of zinc (aluminum) reveals a good agreement assuming a reduction of the effective silicon capping layer thickness by approximately 1.3 (3.0) $\mathrm{nm}$. This suggests that the degree of SPC-induced redistribution/diffusion in the proximity of the $\mathrm{Si} / \mathrm{ZnO}: \mathrm{Al}$ interface is more pronounced for aluminum than for zinc.

The diffusion of both elements - zinc and aluminum - could have a detrimental effect on the electronic quality of the n-doped silicon emitter, limiting the power conversion efficiency of resulting polycrystalline silicon thin-film solar cells. Aluminum acts as acceptor in silicon and therefore could (partially) compensate the phosphorous doping in the solar cell emitter. Zinc, however, may establish a deep defect in silicon [19] which can act as a recombination center. Thus, the observed zinc diffusion into the silicon may be more detrimental with respect to the device performance.

The next step in the manufacturing of the polycrystalline silicon thin-film solar cell after SPC annealing is a rapid thermal processing (RTP) step. Since the RTP annealing is performed at even higher temperatures, further studies are required to reveal whether this treatment may lead to even stronger chemical interactions. The ultimate goal of these studies is a knowledge-based solar cell design optimization preventing such detrimental effects at the Si/ZnO:Al interface.

\section{Summary and Conclusion}

In the present study, HAXPES was used to analyze chemical interactions at the buried Si/ZnO:Al interface upon SPC annealing. Expanding on the earlier reported SPC-enhanced formation of Si- $\mathrm{O}_{\mathrm{x}}$ bonds at the interface, in which the $\mathrm{ZnO}$ layer acts as the oxygen source, in this investigation we focused on the impact of the SPC 
annealing on the (re)distribution of aluminum and zinc. Monitoring Si $2 s$ and $\mathrm{Zn} 3 \mathrm{~s}$ photoemission lines using various excitation energies, we were able to identify a relative intensity increase of the $\mathrm{Zn} 3 \mathrm{~s}$ signal after annealing. In addition, a shift of the $\mathrm{Si} 2 \mathrm{~s}$ to higher binding energies was observed, which was interpreted as being indicative of a shift of the Fermi level due to SPC-induced dopant activation. In addition to the increased $\mathrm{Zn}$ 3s intensity, an enhanced Al 1s photoemission line intensity was found after SPC annealing. In agreement with the simplest explanation model, these increased intensities were interpreted as an indication for zinc and aluminum diffusion into the silicon emitter. Quantification of the respective intensity ratios showed that this redistribution in the proximity of the Si/ZnO:Al interface seems to be more pronounced for the aluminum compared to zinc. These SPC-induced chemical interaction processes need to be taken into account when further optimizing/developing the polycrystalline thin-film silicon PV technology.

\section{Acknowledgments}

E. Conrad, M. Mertin and F. Schäfers are acknowledged for technical support. M.W., F.R., and J.H. thank the Federal Ministry for the Environment, Nature Conservation and Nuclear Safety (No. $0327693 \mathrm{H}+\mathrm{A}$ ) and R.G.W., D.G., R.F., and M.B. acknowledge the Helmholtz Association (VH-NG-423) for financial support. 


\section{References}

[1] M. A. Green, K. Emery, Y. Hishikawa, W. Warta, and E. D. Dunlop, Prog. Photovolt.: Res. Appl. 20, 12 (2012).

[2] K. L. Chopra, P. D. Paulson, and V. Dutta, Prog. Photovolt.: Res. Appl. 12, 69 (2004).

[3] B. Rech, and H. Wagner, Appl. Phys. A 69, 155 (1999).

[4] O. Vetterl, F. Finger, R. Carius, P. Hapke, L. Houben, O. Kluth, A. Lambertz, A. Mück, B. Rech, and H. Wagner, Sol. Energy Mater.Sol. Cells 62, 97 (2000).

[5] M. A. Green, Appl. Phys. A 96, 153 (2009).

[6] D. Amkreutz, J. Müller, M. Schmidt, T. Hänel, and T. F. Schulze, Prog. Photovolt.: Res. Appl. 19, 937 (2011).; F. Falk, G. Andrä, J. Cryst. Growth 287, 397 (2006).

[7] M. J. Keevers, T. L. Young, U. Schubert, and M. A. Green, Proceedings of the 22nd European Photovoltaic Solar Energy Conference, Milan, Italy, p. 1783 (2007).

[8] O. Kluth, B. Rech, L. Houben, S. Wieder, G. Schöpe, C. Beneking, H. Wagner, A. Löffl, and H.-W. Schock, Thin Solid Films 351, 247 (1999).

[9] T. Sontheimer, C. Becker, F. Ruske, C. Klimm, U. Bloeck, S. Gall, O. Kunz, T. Young, R. Egan, J. Hüpkes, and B. Rech, Proceedings of the $35^{\text {th }}$ IEEE Photovoltaic Specialists Conference, Honolulu, USA, p. 614 (2010).

[10] C. Becker, F. Ruske, T. Sontheimer, B. Gorka, U. Bloeck, S. Gall, and B.Rech, J. Appl. Phys. 106, 084506 (2009).

[11] M. Wimmer, M. Bär, D. Gerlach, R. G. Wilks, S. Scherf, C. Lupulescu, F. Ruske, R. Félix, J. Hüpkes, G. Gavrila, M. Gorgoi, K. Lips, W. Eberhardt, and B. Rech, Appl. Phys. Lett. 99, 152104 (2011).

[12] F. Ruske, M. Roczen, K. Lee, M. Wimmer, S. Gall, J. Hüpkes, D. Hrunski, and B. Rech, J. Appl. Phys. 107, 013708 (2010).

[13] M. Gorgoi, S.Svensson, F. Schäfers, G. Öhrwall, M. Mertin, P. Bressler, O. Karis, H. Siegbahn, A. Sandell, H. Rensmo, W. Doherty, C. Jung, W. Braun, and W. Eberhardt, Nucl. Instr. Meth. A 601, 48 (2009). 
[14] The Gaussian contributions to the Voigt profiles used to fit the Au $4 f$ photoemission lines of a clean gold reference were taken as measure for the experimental resolution.

[15] IMFP values calculated for $\mathrm{Si}$ using the QUASES-IMFP-TPP2M code, www.quases.com, which is based on S. Tanuma, C. J. Powell, and D. R. Penn, Surf. Interface. Anal. 21, 165 (1993).

[16] M. Bär, M. Wimmer, R.G. Wilks, M. Roczen, D. Gerlach, F. Ruske, K. Lips, B. Rech, L. Weinhardt, M. Blum, S. Pookpanratana, S. Krause, Y. Zhang, C. Heske, W. Yang, and J.D. Denlinger, Appl. Phys. Lett. 97, 072105 (2010).

[17] R. A. Street, Hydrogenated amorphous silicon, Cambridge University Press, 1991.

[18] The observed intensity increase of the $\mathrm{Zn} 3 \mathrm{~s}$ and Al 1s core levels cannot be explained by changes in the silicon structure or enhanced surface oxidation. On one hand the increase in density of the silicon capping layer upon the SPC-induced conversion of amorphous into polycrystalline silicon results in a corresponding reduction in film thickness. Thus the lower IMFP in crystalline silicon (compared to that in amorphous silicon) is in a first approximation counterbalanced by the decrease in thickness of the attenuating layer. On the other hand the increasing silicon surface oxidation upon SPC would result in the increase of the capping layer thickness actually leading to an increase in signal attenuation. This suggests that the estimation on the basis of the observed increase of zinc and aluminum signal intensity upon SPC is a lower bound for the degree of chemical interaction in the proximity of the Si/ZnO:Al interface. Note that due to the SPC also the hydrogen content in the silicon is reduced, but this is considered to only have a minor (negligible) impact on the signal attenuation of the silicon capping layer.

[19] C. S. Fuller and R. J. Morin, Phys. Rev. 105, 379 (1957). 


\section{Figures}

Fig. 1. Schematic presentation of a typical polycrystalline silicon thin-film solar cell as investigated in Ref. [10]: In this so called superstrate configuration the light is entering the solar cell after having passed a glass substrate. The glass is coated with a diffusion barrier (e.g., silicon nitride). The phosphorous-doped silicon [poly-Si(P)] is deposited on top of the substrate and forms the emitter of the solar cell. The absorber (poly-Si) is slightly doped with boron and the base [poly- $\mathrm{Si}(\mathrm{B})]$ is highly doped with boron. Implementing a transparent conductive oxide layer (as e.g., ZnO:Al) in between the glass substrate and the silicon layers would greatly simplify the electrical contacting of the solar cell. Typical thicknesses for the different layers are shown on the left. The electrical back contact of the cell is not shown.

Fig. 2. Si 1s photoelectron spectra before ("as-deposited") and after SPC annealing ("annealed") for five excitation energies between 2010 and $8040 \mathrm{eV}$. The spectra are normalized to the maximum of the Si-Si feature. The high-binding energy feature can be attributed to $\mathrm{Si}-\mathrm{O}_{x}$ bonds. Modified from [11].

Fig. 3. (a) Si 2 s and $\mathrm{Zn} 3$ s photoelectron spectra before ("as-deposited") and after SPC annealing ("annealed") for six different excitation energies (2010 - $8040 \mathrm{eV})$. The spectra are shown normalized to the maximum of the Si 2s Si-Si feature. (b) Enlarged presentation of the $\mathrm{Zn} 3 \mathrm{~s}$ photoemission line.

Fig.4. Binding energy (BE) shifts of the Si $2 s$ and the $\mathrm{Zn}$ 3s core levels due to SPC annealing [BE (after annealing) - BE (before annealing)] shown as a function of the IMFP in silicon [15] for the spectra in Fig.3. 
Fig.5. Al 1s photoelectron spectra before ("as-deposited") and after SPC annealing ("annealed") for five excitation energies between 2010 and $6030 \mathrm{eV}$. The spectra are shown normalized to the background.

Fig.6. The ratio of the normalized intensities of $\mathrm{Zn} 3 \mathrm{~s}$ and $\mathrm{Al}$ 1s core levels after (ISPC) and before annealing $\left(\mathrm{I}_{\mathrm{AD}}\right)$ shown as a function of the electron IMFP [15]. The dashed and solid lines indicate the expected intensity ratio decrease if the effective silicon capping layer thickness is reduced by 1.3 and $3.0 \mathrm{~nm}$, respectively. 
$\sim 50 \mathrm{~nm}$

$\sim 1.5 \mu \mathrm{m}$

$\sim 30 \mathrm{~nm}$

$\sim 800 \mathrm{~nm}$

\section{poly-Si (B)}

\author{
poly-Si
}

\section{poly-Si (P)}

\section{ZnO:Al}

\section{diffusion barrier}

glass

light 
Figure 2
Click here to download high resolution image

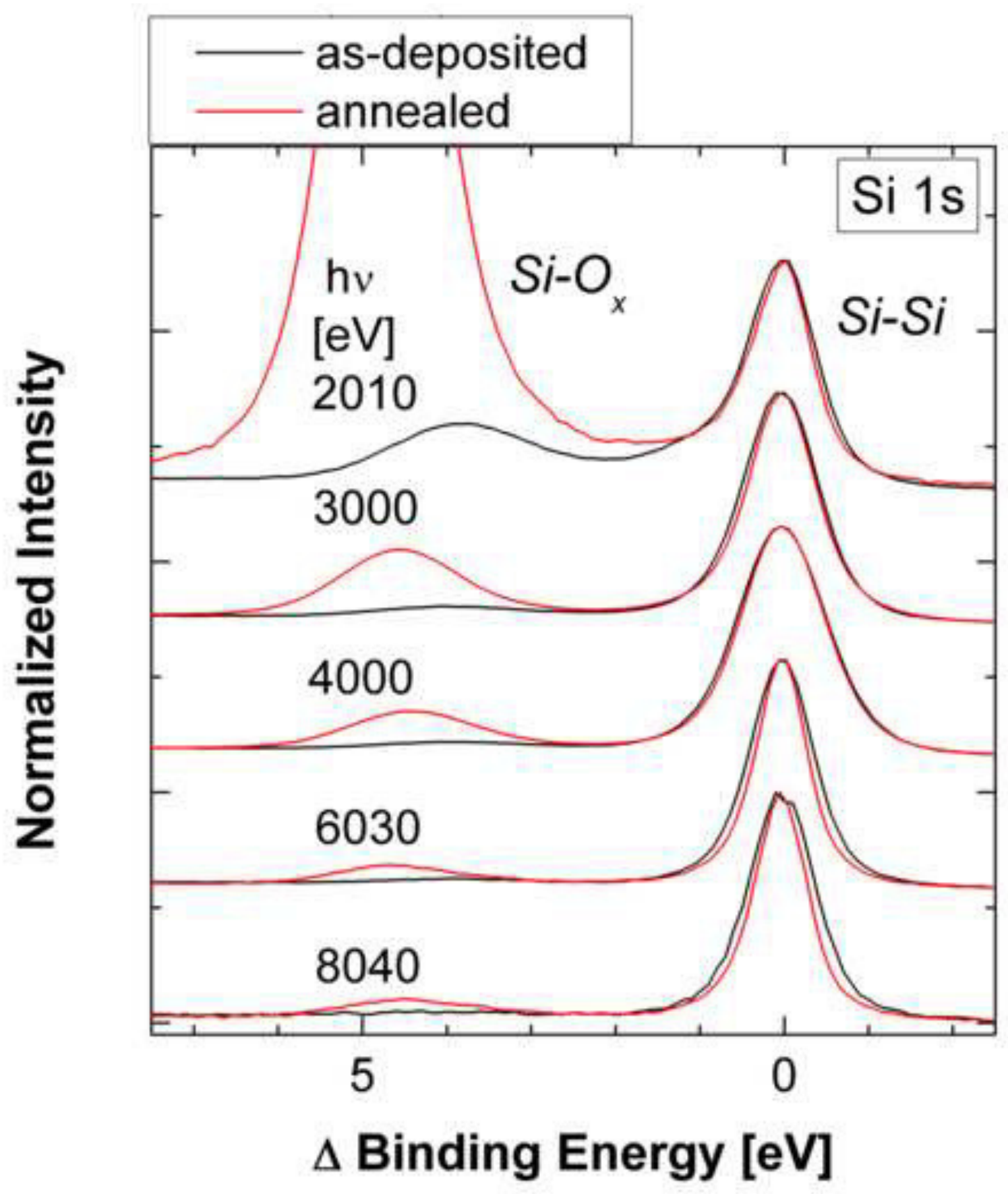




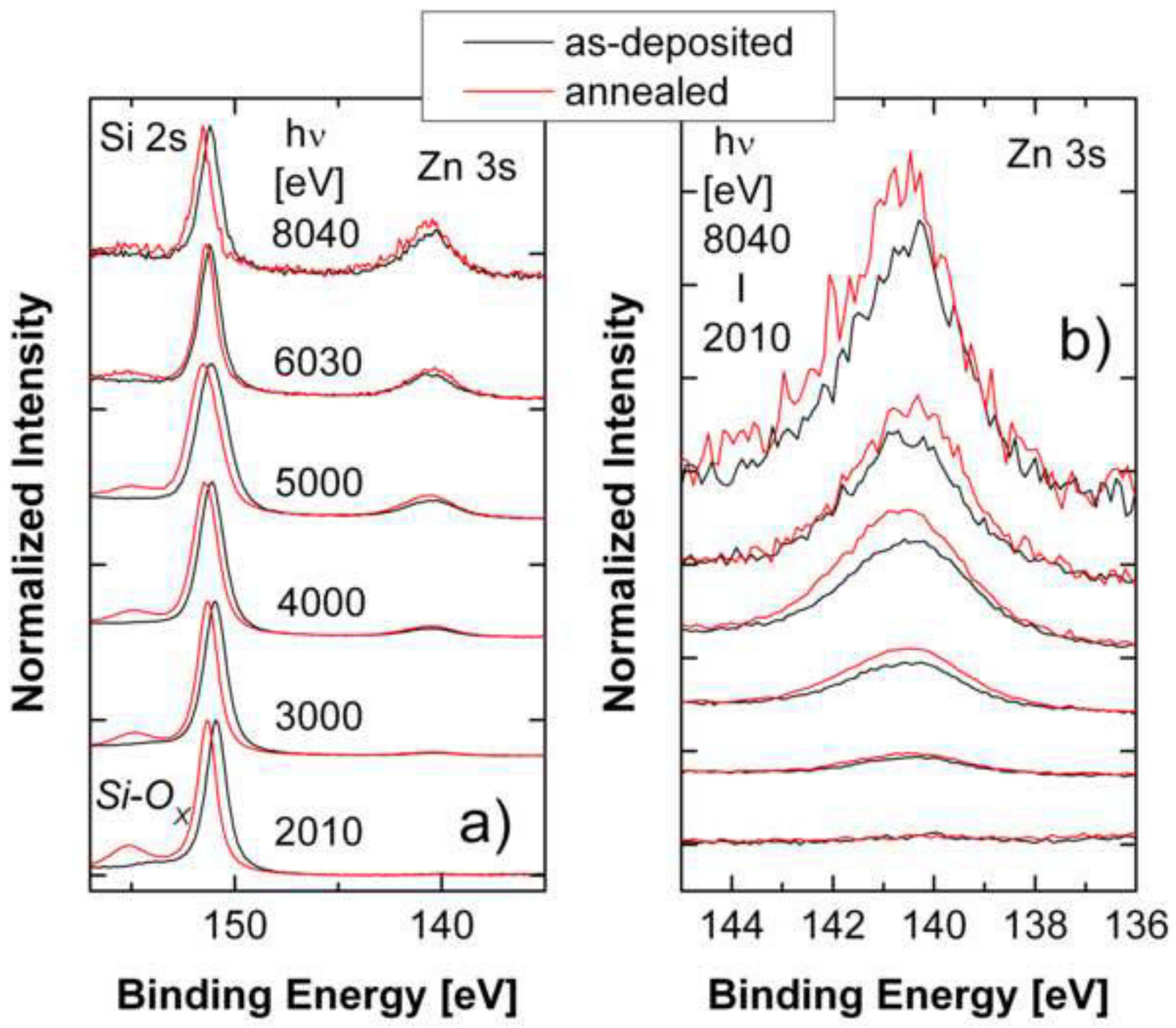


Figure
Click here to download high resolution image

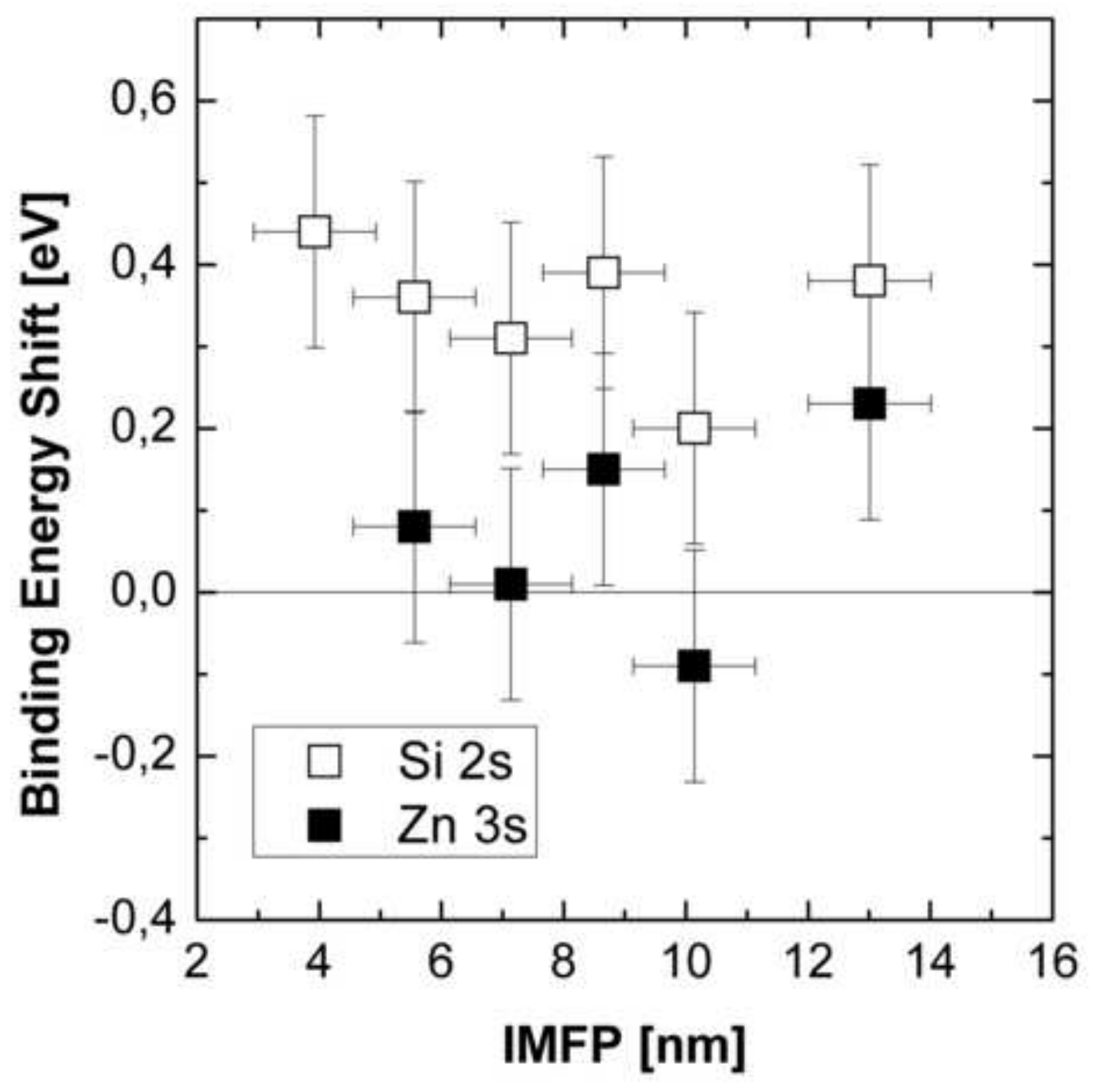




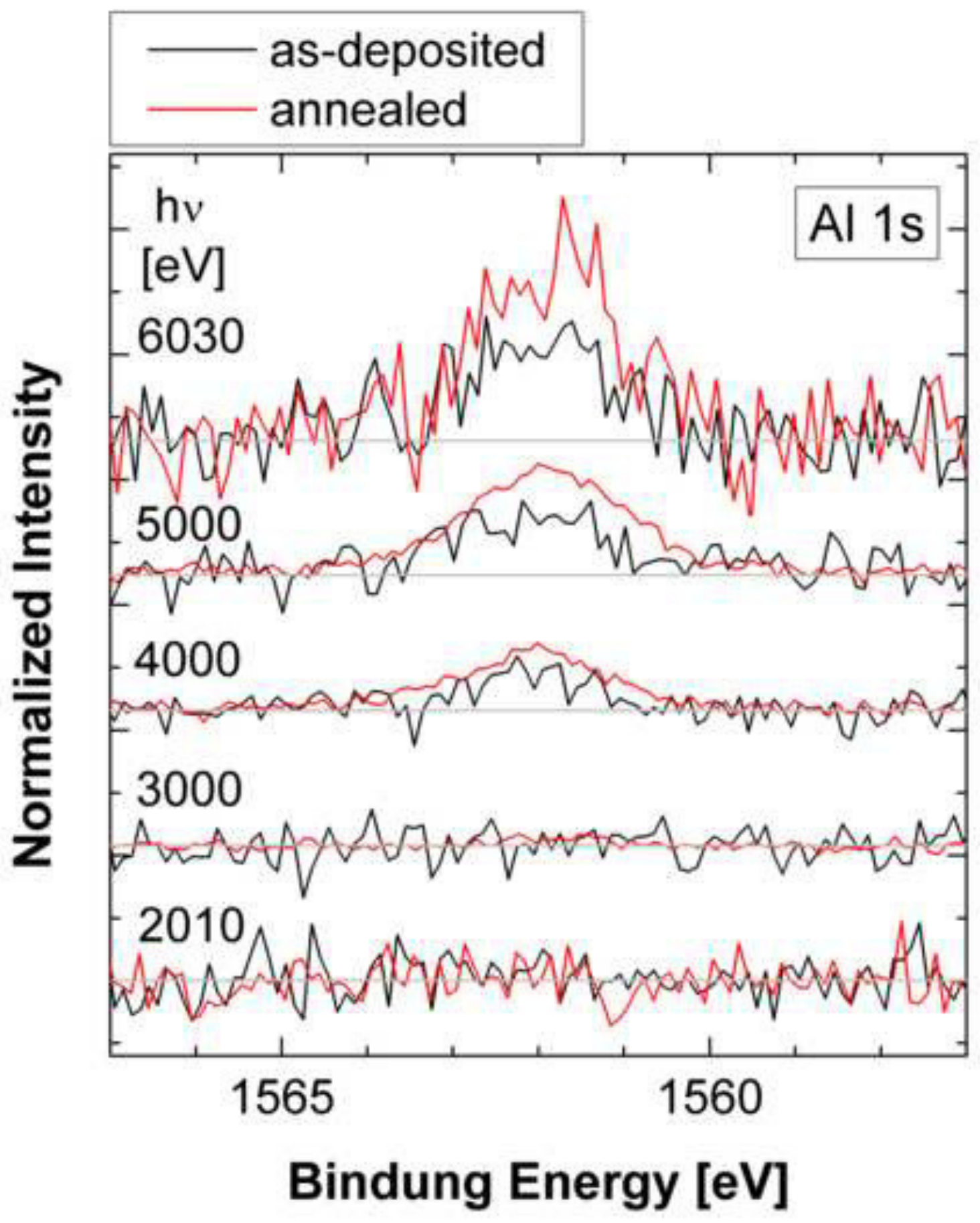




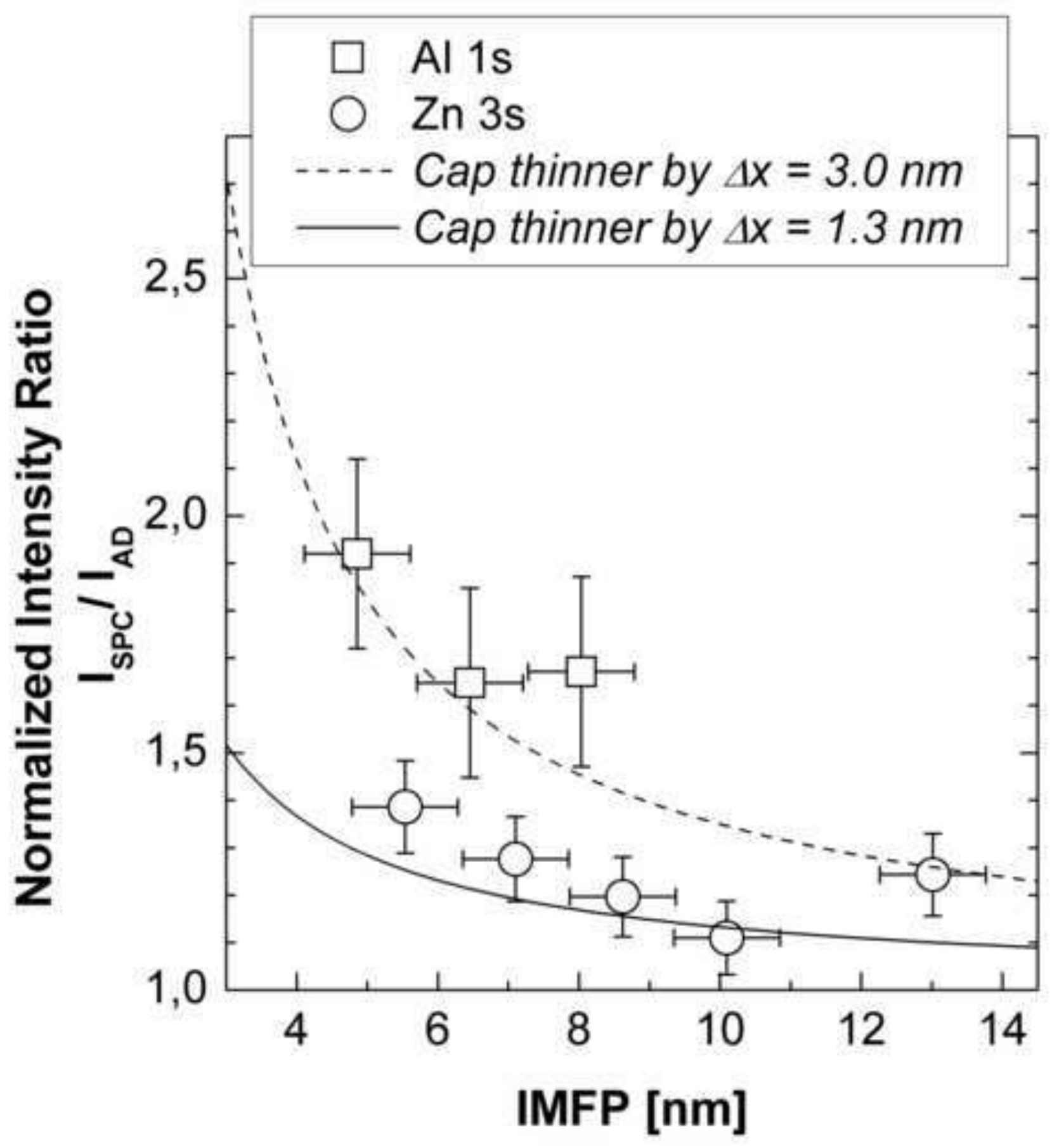

